\title{
Verbal Working Memory and Short-term Memory: Bilingual vs Monolingual Children
}

\author{
BURHAN OZFIDAN \\ Florida Gulf Coast University, \\ United State of America \\ \& \\ Prince Sultan University, \\ Kingdom Saudi Arabia \\ bozfidan@fgcu.edu
}

\begin{abstract}
Language learning is an incredible process for children. The study aims to assess the effect of early L2 immersion on L1 development and phonological working memory, and short-term memory. Specifically, the researcher compared the performance of a group of bilinguals and monolinguals aged 5-7. This study from a cognitive perspective supports the hypothesis that exposure to an L2 in sequential bilingual children exerts an affirmative influence on their cognitive development. There were 56 Turkish-speaking upper-middle-class students as participants of the study. The researcher designed to examine the impact of L2 learning on phonological shortterm and working memory development by performing tasks measuring phonological working memory and shortterm memory and L1 linguistic skills in a group of bilinguals and monolinguals. The findings reflected that bilingual students outperformed their monolingual peers once the bilinguals' performance with monolinguals was compared to all possible variables. The study results support the hypothesis that intensive and early exposure to an L2 may increase verbal working memory and verbal short-term memory abilities in sequential bilingual children while not decreasing their linguistic performance in L1. The results of articulatory abilities, naming, phonological discrimination, sentence completion, and grammatical comprehension assessments indicated that bilinguals notably performed better than monolinguals. This indicates that exposure to L1 enables bilingual children to develop the L1 for a significant amount of time sufficiently.
\end{abstract}

Keywords: bilingual; monolingual; working memory; verbal working memory; short-term memory

\section{INTRODUCTION}

The current study investigated the effect of early L2 immersion on L1 development, phonological working memory, and short-term memory. Specifically, the researcher linked the performance of a cohort of bilinguals and monolinguals aged 5-7. Furthermore, the researcher hypothesised that exposure to the second language would improve their phonological shortterm memory and working memory abilities. Lastly, the researcher also hypothesised that bilingual children's phonological, lexical, and grammatical abilities could be like those detected in monolinguals.

The researcher hypothesised that exposure to the L2 would improve phonological working memory abilities (assessed by one complex span task) and phonological short-term memory (assessed with two simple span tasks). Furthermore, although researcher highlight that the active rehearsal process essential to do well in such tasks is still not entirely functional in monolinguals before the age of 6 (Marini et al., 2019; Baddeley, 1986), the researcher hypothesised that the constant exposure to the L2 would improve this executive ability within the bilingual children (Henderson, 2017; Johnson et al., 2019; Kehoe, \& Mélanie, 2019). Eventually, as bilingual children had been exceptionally exposed to their first language until three years of age and since then had been exposed to their L1 for at least $60 \%$ of their weekly time, the researcher also hypothesised that the phonological, grammatical and lexical abilities of the bilinguals would be like those observed in the monolinguals. 
According to Morales et al. (2013), working memory is a cognitive scheme with a limited capacity to keep information momentarily. According to Baddeley (2003), working memory is vital for reasoning and the guidance of behaviour and decision-making. Working memory is usually used with short-term memory synonymously. However, some researchers highlight these two systems of memory different, supposing that working memory permits the stored information manipulation although short-term memory just states to the short-term storage of information.

Verbal working memory (VWM) is accountable for momentarily keeping verbalisable information, for instance: numbers, words, letters, or nameable objects. A powerful structure in which the VWM consists of a phonological circle (Baddeley, 2003). The phonological circle, according to Baddeley, includes two subcomponents: "(1) a passive storage process that lasts 1-2 seconds and (2) an active articulatory control process" (p.192). The active process, according to Baddeley and Hitch (1974), "translates visually presented verbal content into a phonological representation that can be maintained in phonological storage (aurally presented information can be directly stored; no translation is required) and refreshes this information by subvocal repetition" (p.198). Thus, VWM is generally considered as the verbal information's temporary maintenance.

Short-term verbal memory (STVM), according to Cowan et al. (1999), consists of 3 modules: "capacity, duration, and encoding." Gathercole and Hitch (1993) stated that capacity highlights the amount of information that an individual could keep in their STVM "a typical rule of thumb is seven items, +/- 2" (p.195). This is also identified as "Miller's Magic Number" and was projected in 1956 once it was discovered that the average adult could keep between 5 to 9 items in STM (Gathercole \& Hitch, 1993). According to Kormos and Sáfár (2008), duration signifies the amount of time an individual could recall the information in his or her STVM. Typically, STVM is thought to last 15-30 seconds. Delays and interruptions generally trigger them to lose the information and damage the content in a person's STVM. Encoding is a technique that may include verbal or mental repetition and rehearsal of the items and can recall STVM (Kormos \& Sáfár, 2008).

Overall, the study's findings highlight the hypothesis that intensive and early exposure to L2 may enhance VWM and VSTM abilities in sequential bilingual children while they are not decreasing their linguistic performance in L1. Nevertheless, there are some empirical limitations of the current study. First, the researcher conducted linguistic analyses on the participants' L1. This did not allow the researcher to discover L2's characteristics among the bilingual children while theoretically sound for the purposes of the study. However, at least 2years old, children had consistently been exposed to their L2, and the children's teachers found no difficulties in its mastery or use. The second limitation was the number of bilingual children. Further studies could be with greater samples of the students (participants), which would allow researcher to perform better analyses statistically.

\section{RESEARCH QUESTIONS}

Our main research question was, "What is the impact of L2 learning on the development of phonological short-term and working memory? And how about its impact on first language development? Is it necessarily detrimental?" By performing tasks measuring phonological working memory and short-term memory as well as L1 linguistic skills in a group of bilinguals and monolinguals, the researcher designed to examine these questions. 


\section{VERBAL WORKING MEMORY AND SHORT-TERM MEMORY}

The term "working memory", according to Baddeley (2003), highlights the capacity to manipulate and store information for a while. According to Baddeley, "working memory capacity is measured by complex span tasks that require simultaneous short-term storage of information while processing additional, and sometimes unrelated, information" (p. 201). Last three decades, researcher found that working memory is not only a store; however, a memory system consisted of separate interacting mechanisms. These mechanisms, functioning together, deliver a sort of flexible mental workspace that acts as a momentary bridge between internally and externally produced mental representations and that can be used to convert and maintain information while challenging cognitive activities. Therefore, it is essential to differentiate short-term memory from the correlated concepts of working memory. However, several researchers explained the terms "short-term memory" and "working memory" as identical, and truly the term "working memory" slowly replaces the term "short-term memory" in the literature.

Conversely, according to Baddeley, "working memory was initially adopted to transfer the idea that active processing, as well as passive storage, is involved in temporary memory" (p.203). Though Baddeley (2003) reflected "verbal working memory" as a functionally separable presence, this "device" seems to comprise a "sensorimotor coding mechanism" (Buchsbaum \& D'Esposito, 2008), "overlapping with the mental lexicon" on the one hand and "the speech production system" on the other (Gathercole \& Hitch, 1993). Additionally, according to Baddeley (2003), "working memory must be considered a resource recruited both by the speech production and the speech perception apparatus because we would not be able to process longer and syntactically structured sentences in the absence of such a short-term storage mechanism" (p.202).

Verbal working memory (VWM) investigations have produced several robust phenomena about behavioural performance in VWM tasks (Gathercole \& Baddeley, 1990; Marini et al., 2019). Since these phenomena are the performance designs that have stood the test of replication and deliver information regarding the nature of the verbal material's processing architecture underlying maintenance, they are central to any theory of VWM. Therefore, VWM models should explain these phenomena. The core phenomena include phonological similarity, concurrent articulation, word length, irrelevant sound, serial position, and presentation modality (O'Toole \& Hickey, 2013; Johannessen, 2019; Ozfidan \& Mitchell, 2020; Peets et al., 2019).

Linguistic distinctions in short-term memory performance are not found only crosslinguistically but also found in bilingual groups (Marini et al., 2019; Beatty-Martínez \& Dussias, 2017; Ziglari \& Ozfidan, 2016; Dos Santos \& Ferré, 2018). For instance, Ellis and Hennelly (1980), in a usually cited set of experiments, highlighted that even though Welsh English bilingual people's self-rated proficiency was higher in Welsh than in English, these people had a greater digit span in the language with the shorter digit names (English). According to Zavala (2018), "this, and the absence of a language difference under experimental conditions that disrupt subvocal rehearsal, led the authors to claim that bilingual language differences in recall performance, like cross-linguistic differences, can be attributed to subvocal rehearsal rate differences" (p. 1320). Doubting on the understanding that subvocal practice rate differences are only accountable for language distinctions in the bilingual memory performance.

One of the significant issues highlighted by this study is whether the working memory's theoretical structure is subject to changes as a developmental growth function or is coherent across childhood. For example, in order to perform short-term memory tasks, younger children draw more on executive resources. According to Baddeley (1986), this is because "the brain 
areas related to higher-level cognition are still developing, and while older children will have acquired greater cognitive resources, younger children will not have the benefit of these additional support systems" (p. 107). Another possibility, according to Baddeley (1986), "the working memory structure remains consistent across development" (p. 107).

According to Engel de Abreu (2011), second-language learners benefit from Verbal short-term Memory (VSTM) or VWM. For instance, according to Morales et al. (2013), bilingual groups ranging from 5- to 7- years old surpassed monolingual children in a visuospatial span task presenting a bilingual benefit in working memory. Such benefit could also be extended to VWM and VSTM, as clearly indicated in the study of Linck et al. (2014), where it is recommended that processes of VSTM and VWM have a vigorous affirmative association with second language results. Additionally, Linck et al. propose different outcomes of L2 proficiency on the working memory's different components: "the processing component (i.e. VWM) was found to be more related to L2 outcomes than the storage component (i.e. VSTM)" (p. 865). Therefore, typical characteristics of working memory can be formed by L2 ability. Further aspects could also influence children's performance on such tasks. According to Gámez et al. (2019), "socio-economic status (SES) anticipated working memory performance at 53 months in a study on a large cohort of children" (p. 474). Remarkably, early SES effects kept coherent through middle childhood (Gámez et al. 2019). In the research by Gámez et al. (2019), it is highlighted that "all participants were middle- to upper-middle class and that on average parents had accomplished 12 years of education" (p.475). Nevertheless, the confirmed range of parents educational background " $\min =6$; $\operatorname{Max}=16$ " was reasonably high, leaving open the prospect of inadequate control of the effect possibly used by this variable on working memory abilities. Likewise, performance on such tasks could also rely on the variety of bilingualism. According to Hackman et al. (2015), "simultaneous bilinguals, who have been exposed to two languages since birth, might switch between them using automatic procedures" (p. 692). This could decrease the need to recruit extra working memory sources. By contrast, according to Parker-Jones et al. (2012), "sequential bilinguals might still need to explicitly control their two languages keeping track of ongoing linguistic processes while using their L2" (p.895). That could cause improved VWM processing and VSTM capacity. Thus, the researches measuring a possible bilingual influence on VSTM and VWM are still not effective. Additional study is essential to create the effect possibly exerted by bilingualism on VWM and VSTM.

\section{RESEARCH METHOD}

\section{PARTICIPANTS AND PROCEDURES}

There were 56 Turkish-speaking participants in the study, which was conducted in 2019. All participants were from the upper-middle class. In an initial interview, the teachers of the participants (students) indicated that all participants had normal learning and cognitive development. According to the records of the school and parents, none of the students had a known history of neurological or psychiatric disease, learning disabilities, visual or hearing loss. In addition, parents and teachers delivered each student's family demographic background and daily language usage. 
3L: Language, Linguistics, Literature ${ }^{\circledR}$ The Southeast Asian Journal of English Language Studies Vol 27(3), September 2021 http://doi.org/10.17576/3L-2021-2703-11

TABLE 1. The participants of two groups showing the main characteristics

\begin{tabular}{|c|c|c|c|c|c|c|}
\hline & Age & $\begin{array}{c}\text { Formal } \\
\text { education/Years }\end{array}$ & $\begin{array}{c}\text { Education of } \\
\text { parents }\end{array}$ & Gender & Handedness & $\begin{array}{l}\text { Raven's } \\
\text { Matrices }\end{array}$ \\
\hline Monolingual & $5.61(.50)-$ & $3.48(.51)$ - Range: & $15.71(2.22)-$ & $\mathrm{M}=12$ & Right- & $17.51(3.87)-$ \\
\hline $\begin{array}{l}\text { School } \\
(\mathrm{N}=28)\end{array}$ & $\begin{array}{c}\text { Range: } 5.02- \\
6.11\end{array}$ & $3-4$ & Range: $12-17$ & $(42.9 \%)$ & $\begin{array}{c}\text { handed = } \\
25(89.2 \%)\end{array}$ & Range: $12-26$ \\
\hline Bilingual & $5.60(.50)-$ & $3.48(.51)$ - Range: & $15.71(2.22)-$ & $M=13$ & Right- & $15.59(3.91)-$ \\
\hline $\begin{array}{l}\text { School }(\mathrm{N}= \\
28)\end{array}$ & $\begin{array}{c}\text { Range: } 5.02- \\
6.11\end{array}$ & $3-4$ & Range: $12-17$ & $(46.4 \%)$ & $\begin{array}{c}\text { handed }= \\
25(89.2 \%)\end{array}$ & Range: 8-26 \\
\hline
\end{tabular}

Note: "Mean (standard deviations) and ranges of the performance of the two groups."

The demographic data of the study was designed as a control and an experimental group by matching chronological age, formal education level, gender, handedness, and socioeconomic status based on the parents' educational background. As analysed by performing Raven's progressive matrices, Table 1 indicated that these two bilingual and monolingual children had similar non-verbal logical reasoning. For the study's experimental group, 28 bilingual participants (students) were attending an international (private) school in Turkey. All students were natives in Turkish between 5.03 and 6.12 years "mean: 5 years and 7 months, SD: .50" and attended the international school for two to three years. All these students had significantly been exposed to English when they entered school only from the age of 3. These students had been exposed to English (as a second language) for 7 hours a day and used it with their friends and teachers in school each day, but not included weekends (weekly time $40.7 \%$ ). At the same time, they used Turkish, which is their first language, daily and during the weekends (weekly time 59.3\%).

For the control group, 28 students were attending a monolingual school in Turkey. The first language of all these students was Turkish who were aged between 5.03 and 6.12 years "mean: 5 years and 7 months, SD: .50", and they were wholly exposed to their native language (Turkish) and only slightly (4 hours per week) compared to their exposure to English at their school. These participants were selected from 1250 students. The normal range on Raven's progressive matrices was performed for all participants (Raven, 2000). All of the participants also performed within the non-word repetition subtest of the BVL_4-12 "Battery for Language Assessment in Children from 4 to 12 years" (Note: the original documents translated from Italian into Turkish and English) (Marini et al., 2019), and on the Wechsler's (1993) the forward and backward digit recall subtest scales.

Both of the groups, as indicated in Table 1, had a parallel chronological age " $\mathrm{t}(56)=$ $-.012 ; \mathrm{p}=.980$ ", former education years " $\mathrm{t}(56)=.000 ; \mathrm{p}=1.000$ ", education of the participants' parents " $\mathrm{t}(56)=.001 ; \mathrm{p}=.990)$, and level of logical non-verbal reasoning as measured with Raven's Progressive Matrices $\mathrm{t}(56)=-1.867 ; \mathrm{p}=.075$ ". Additionally, the participants didn't differ on handedness ' $\chi 2=1.000 ; p=.549$ " or gender " $\chi 2=.057 ; p=.789$ ".

Trained developmental psychologists assessed students' phonological working memory and short-term memory and linguistic skills in a silent classroom at the students' schools. All parents signed the informed consent forms to allow their children to join the study.

\section{EVALUATION OF PHONOLOGICAL WORKING MEMORY AND SHORT-TERM MEMORY}

To assess phonological working memory and short-term memory of the participants, they were given three different tests: "the forward digit recall subtest of the Wechsler Scales (Wechsler, 1993); the non-word repetition subtest of the BVL_4-12 (Marini et al., 2015; Marini et al., 2019); and one complex span task: the backward digit recall subtest of the Wechsler Scales (Wechsler, 1993)." The participants (students) were requested to repeat the digits' spoken sequences for the forward digit recall test in the proper serial order. The psychologists, who assessed the students, formed sequences ranged from 1 to 9 digits and formed at the rate of 1 
digit per second. The backward digit recall assessment was the same as the forward digit recall exam. The students were requested to repeat the digits' spoken sequences in reverse order to assess the backward digit recall. The students were asked to repeat 15 non-words, which followed the Turkish language's phonotactic rules for the non-word repetition task. The stimuli were planned to increase the complexity levels of the students progressively. When the students correctly reproduced all of the consonants and vowels in the word, the examiner considered a correct repetition.

\section{PROCEDURES OF LINGUISTIC ASSESSMENT}

By administering the BVL_4-12, the researcher assessed the participants' linguistic skills (Marini et al., 2015; Marini et al., 2019). The BVL_4-12 is a battery of tests purposed to measure children's (aged from 4 to 12) language abilities along with three methods, "i.e., repetition, comprehension, and production," from phonetics to pragmatics. The students were given three tests in two different sessions, which nearly took 40 minutes each. The students were first given a cohort of tests measuring narrative and linguistic production. Next, they were given tests to assess comprehension and repetition abilities. Finally, the researcher also reported the performance of these students on the test to assess grammatical and lexical comprehension and production.

\section{ASSESSMENT OF PRODUCTION ABILITIES}

The researcher assessed the students ' lexical production abilities by administering tasks measuring sentence completion, naming, and articulatory skills. By using the naming subtest of the BVL_4-12, the researcher assessed articulatory and naming abilities. The students in sheets were asked to name 77 stimuli depicted. The stimuli were elected to characterise words with various frequencies in Turkish "words with high, medium, and low frequency", various grammar classes (nouns and verbs), and semantic features (action nouns and verbs relating to 16 semantic classifications). The test included both an articulation and a naming score. If a participant (student), for each item, formed the target word and expressed (spoken) it precisely, then he/she was given two marks for articulation and one mark for naming. If a participant (student), for each item, produced wrongly or did not produce any word, then he/she was given a 0 mark for naming. The students were asked to repeat the target words, and if any of them repeated correctly, they received a mark of 1 , but if they did not repeat the target words correctly, they were given a 0 mark for articulation. The highest articulation score was 155, and the highest naming score was 77 .

To develop inflectional and derivational morphology while constructing well-formed sentences grammatically, the BVL_4-12's sentence completion subtest measured the students' skills. Each student, namely, listened to a sentence "the model; e.g., Marco kapıyı açar (Marco opens the door)" and then listened to the beginning of a second sentence, "the prompt", which they were requested to complete by conveying the right morphemes to the verb "the target". In the sample, the prompt was "Bizde... (in English: We also ...)," and the students were anticipated to write the target sequence as follows: "Bizde kapıyı açıyoruz (in English: We also open the door)." The test with different grammatical complexity levels included 14 pairs of model prompts and sentences. Students were given one mark for each correct answer, and students were given a 0 mark if they did not make a sentence correctly. The highest score was 14 for sentence completion. 


\section{ASSESSMENT OF COMPREHENSION ABILITIES}

The researcher analysed comprehension abilities by performing tasks measuring grammatical and lexical abilities, "i.e., tests of phonological discrimination, lexical, and grammatical comprehension." In the assessment of phonological discrimination, the students listened to 30word pairs totally: 10 couples of identical items and 20 minimal pairs, "i.e., words that differ for only one phoneme, such as in cane - pane." The students for every word-pair were asked to discuss whether the words were the same or not. Every student received one mark for every correct judgment, and the highest score was 30 .

Among four pictures, the students were required to recognise the meaning of 18 series words, which were all high-frequency nouns in Turkish, uttered by the examiner in the BVL_412's lexical comprehension subtest. The students, after listening to every stimulus word "e.g., cat," were provided with a sheet of paper with one target picture, "e.g., the one corresponding to the meaning of the word produced by the examiner -cat" accompanied by one semantic, "e.g., a picture portraying the meaning of a word which is only semantically related to the target word -dog," one phonological "e.g., a picture portraying the meaning of a word that was phonologically related to the target word -car," and one unconnected distracter, "e.g., table." The students got one mark for every correct answer. For lexical comprehension, the highest score was 18 .

The students in the grammatical comprehension task were requested to pair every forty sentences of rising complexity with one picture (in 4 pictures) " 1 target picture portraying the meaning of the sentence produced by the examiner and three distracters representing the meanings of alternative sentences that differed from the target in the presence of inverted thematic roles or other morphosis-tactic alterations." The students for every correct answer got 1 point, and the highest score was 40 for grammatical comprehension.

\section{RESULTS}

\section{RESULTS OF PHONOLOGICAL WORKING MEMORY AND SHORT-TERM MEMORY}

The researcher with a one-way between-groups multivariate analysis of variance analysed group-related differences measuring students' phonological short-term memory, "i.e., nonword repetition and forward digit recall." The researcher used two dependent variables, which were forward digit recall and non-word repetition. The students who were attending bilingual and monolingual school systems were the independent variable. After checking for linearity, normality, homogeneity of variance-covariance matrices, multivariate and univariate outliers, and multicollinearity for which no significant violations were noticed, the researcher conducted preliminary assumption testing. Partial eta squared measured the effect sizes. The combined dependent variables " $F(2,57)=9.814$; Wilk's $\lambda=.741 ; p<.001 ; \eta 2=.259$ " exhibited significant group-related differences. After Bonferroni correction for multiple comparisons, the researcher set the statistical significance level at $p<.026 .05 / 2$ dependent variables when the results were considered separately for the dependent variables. The result indicated that the groups varied on both non-word repetition " $F(1,58)=7.231 ; \mathrm{p}<.008 ; \eta 2=.112$ " and forward digit recall " $F(1,58)=18.439 ; p<.001 ; \eta 2=.251$ ". The result in terms of the mean scores (see Table 2) indicated that the students who attended bilingual oriented schools performed better than the monolingual school students in both tasks. 
3L: Language, Linguistics, Literature ${ }^{\circledR}$ The Southeast Asian Journal of English Language Studies Vol 27(3), September 2021 http://doi.org/10.17576/3L-2021-2703-11

TABLE 2. Assessment of phonological working memory and short-term memory

\begin{tabular}{lccc}
\hline & Forward Digit Recall* & Non-word repetition* & Backward digit recall* \\
\hline Monolingual school & $4.95(2.11)-$ & $12.31(2.33)-$ & $1.11(1.34)-$ \\
& Range: $0-10$ & Range: $6-14$ & Range: $0-4$ \\
Bilingual school & $7.21(1.51)-$ & $14.61(1.32)-$ & $1.57(1.35)-$ \\
& Range: $5-10$ & Range: $7-14$ & Range: $0-4$ \\
\hline
\end{tabular}

Notes: "Mean (standard deviations) and ranges of the performance of the two groups. Asterisks $(*)$ show when the grouprelated differences were significant."

A preliminary review as for the phonological working memory measure, "i.e., backward digit recall," indicated that the scores' distribution was skewed in the groups. Within the bilingual students, the researcher detected that nine students $(32.1 \%)$ could not perform the task (in other words, they were scored 0), three students (10.7\%) were scored 1, 10 students $(35.7 \%)$ were scored 2, 3 students $(10.7 \%)$ were scored 3 , and only three students $(10.7 \%)$ were scored 4. Within the monolingual students, the researcher detected that 15 students $(53.6 \%)$ could not perform the task and scored 0,3 students $(10.7 \%)$ were scored 1,6 students $(21.4 \%)$ were scored 2, 3 students $(10.7 \%)$ were scored 3, and only one student $(3.6 \%)$ was scored 4. The researcher used Moses' extreme reaction test to control group-related differences on the continuous scale (from 0 and 4 were the same for both groups). The results in the dispersion of scores $(p<.008)$ indicated a significant group-related difference. In other words, monolingual students' possibility of getting a score of 0 was higher than that of bilingual students, and bilingual students' possibility of getting a score of 4 was higher than monolingual students.

\section{RESULTS OF LINGUISTIC PRODUCTION ABILITIES}

The researcher gave three tasks (three dependent variables: sentence completion, naming, and articulation) to two groups of participants to assess linguistic production skills (see Table 3). The researcher with a one-way between-groups multivariate analysis of variance measured the group-related differences. The group (students who attended monolingual and international schools) was the independent variable of the study. Because the tests for linearity, normality, multivariate and univariate outliers, homogeneity of variance-covariance matrices, and multicollinearity that were conducted found no significant violations, the researcher conducted preliminary assumption testing. Partial eta squared measured the effect sizes. The merged dependent variables " $F(3,61)=1.431$; Wilk's $\lambda=.934 ; p=.241 ; \eta 2=.071$ " did not find significant group-related differences. After Bonferroni correction for multiple comparisons was conducted, the researcher set the statistical significance level at $p<.016 .05 / 3$ dependent variables when the results were considered separately for the dependent variables. Because the students (participants) who attended the international school accomplished the same as the monolingual school students, the result indicated the absence of any group-related difference in these three dependent variables.

TABLE 3. Assessment of linguistic production abilities

\begin{tabular}{llll}
\hline & Articulation & Naming & Naming \\
\hline Monolingual school & $141.44(9.27)-$ & $63.56(4.45)-$ & $7.55(2.30)-$ \\
& Range: $102-149$ & Range: $56-72$ & Range: $4-12$ \\
Bilingual school & $136.61(11.71)-$ & $61.53(5.79)-$ & $7.89(3.12)-$ \\
& Range: $107-151$ & Range: $52-74$ & Range: $3-14$ \\
\hline
\end{tabular}

Note: "Mean (standard deviations) and ranges of the performance of the two groups."

\section{RESULTS OF LINGUISTIC COMPREHENSION ABILITIES}

As preliminary measures indicated, the researcher had violated the homogeneity of variancecovariance matrices assumption "Box's test of equality of covariance matrices: $p<.001$ ". To 
measure linguistic comprehension, "i.e., phonological discrimination, lexical comprehension, and grammatical comprehension," the researcher analysed group-related differences with independent-samples t-tests series. After Bonferroni correction for multiple comparisons, the researcher set the statistical significance level at $p<.016 .05 / 2$ dependent variables. Cohen's $\mathrm{d}$ measured the effect sizes. The researcher found that the groups did not vary in grammatical comprehension " $\mathrm{t}(56)=-.291 ; \mathrm{p}=.781 ; \mathrm{d}=-.073$ " or phonological discrimination " $\mathrm{t}(56)=$ $1.331 ; \mathrm{p}=.189 ; \mathrm{d}=.341 "$ (See Table 4). Nevertheless, in terms of lexical comprehension, students who attended the monolingual school succeeded better than students who attended the International School " $\mathrm{t}(56)=-2.511 ; \mathrm{p}<.015 ; \mathrm{d}=-.651$ ".

TABLE 4. Assessment of linguistic comprehension abilities

\begin{tabular}{lccc}
\hline & Phonological discrimination & Lexical comprehension* & $\begin{array}{c}\text { Grammatical } \\
\text { comprehension }\end{array}$ \\
\hline Monolingual school & $27.31(4.52)-$ & $15.29(1.13)-$ & $27.61(5.29)-$ \\
Bilingual school & Range: $8-28$ & Range: $12-17$ & Range: $9-36$ \\
& $27.60(2.81)-$ & $14.47(1.51)-$ & $27.12(7.69)-$ \\
Range: $15-28$ & Range: $10-16$ & Range: $9-36$ \\
\hline
\end{tabular}

Notes: "Mean (standard deviations) and ranges of the performance of the two groups. The asterisk (*) showed when the group-related differences were significant after Bonferroni correction for multiple comparisons $(\mathrm{p}<.017)$."

\section{DISCUSSION AND CONCLUSION}

This study from a cognitive perspective promotes the hypothesis that exposure to an L2 in sequential bilingual children exerts an affirmative influence on their cognitive improvement. Furthermore, the findings reflected that bilingual students outperformed their monolingual peers when the performance of the bilingual children to monolinguals matched on all possible confounding variables was compared.

The previous researches did not underline any bilingual impact on VWM and VSTM as assessed with related tasks could cause a non-perfect matching between groups. Essentially, as socio-economic status impacts cognitive development and language, it is potential that in such research, this variable had considerably affected the whole group-related performance (Hackman et al., 2015; Ozfidan \& Demir, 2014). Another probability is that also sort of bilingualism could have affected performance on such tasks. For instance, a study by Bialystok (2011) only comprised simultaneous bilingual children. According to Bialystok, "it is possible that sequential bilingual children need to recruit additional resources in their short-term memory in order to manage the processes of L1 and L2 acquisition while monitoring the use of both languages" (p.462). Previous research highlights the identical direction indicating that the role of phonological working memory and short-term memory is superior in less proficient than in more capable bilingual children (Coady, 2020; Guijarro-Fuentes, 2019; Ozfidan, \& Burlbaw, 2019). For instance, in Kremin et al. (2019), low proficiency participants in L2 had bigger short-term memory spans in their L1. By contrast, according to Kremin et al., "those with similar proficiency levels in L1 and L2 did not show this advantage" (p.195). Unfortunately, the researcher did not measure the L2 proficiency level within the bilinguals in the current study. Nonetheless, the researcher assumed that the language use was somewhat less automatic regarding simultaneous bilingual children and hypothesised that this improved their VWM skills and VSTM capacity since they had only been exposed to English from the age of 3 once they started the International School.

The children's VSTM abilities arose from their performance on the non-word repetition task. Bilingual children's good performance on this task supports the hypothesis of "a positive effect of early second language exposure on cognitive development" (García et al., 2017, p. 231). Moreover, according to Schwartz et al. (2018), "the observed bilingual advantage also 
extends to some core systems important for those auditory and attentive skills that are needed for linguistic comprehension and production" (p. 108) because "this is a complex task, which requires the child to analyse the auditory stimulus, and keeps it online in short-term phonological memory as long as it is necessary to convert the heard sequence in a speech plan that must be eventually produced" (p. 109). A recent study, for instance, indicated that early exposure to a second language could increase simple aural perceptual abilities and even develop sustained aural attention (Gass, 2013). This may enlighten why performance on nonword repetition tasks, usually used, helps identify children's language impairments (e.g., Gass, 2013). Moreover, this is a predictor of their lexical learning skill considered in both first languages (e.g., Service 1992; Kohonen \& Service 1995) and second language (e.g., Kroll \& Ma, 2018; Shin, 2017).

The linguistic measures in the current study enabled the researcher to control for the L1 development level in the bilingual student group. The results of articulatory abilities, naming, phonological discrimination, sentence completion, and grammatical comprehension assessments indicated that bilinguals achieved as good as monolinguals. This indicates that exposure to the L1 enables bilingual children to sufficiently develop an L1 for a significant amount of time. Nevertheless, monolingual children had higher lexical comprehension abilities than bilingual children. The results of the study support previous research in which bilingual children exhibited significantly lower achievement than monolingual children in semantic fluency (Ramsden et al., 2012) and had lesser vocabularies than monolinguals, mainly if one of their languages is only considered (Parker et al., 2012; Burgaleta et al., 2016).

To sum up, the study's outcomes support the hypothesis that initial and rigorous exposure to an L2 could improve VWM and VSTM abilities in sequential bilingual children while they are not decreasing their language performance in L1. Nevertheless, there are some empirical limitations of the current study. First, the researcher conducted linguistic analyses on the participants' L1 (Turkish). This did not allow the researcher to discover L2 (English)'s characteristics among the bilingual children while ideally sound for the purposes of the study. However, children had been coherently exposed to their L2 for at least two years, and no problems in its mastery and use had been informed by their instructors at their schools. Another limitation was the decreased number of people in the bilinguals. Further researches ought to investigate whether these results can also be found with a higher sample size. That might allow researcher to achieve more sophisticated statistical studies, such as regression models or factorial designs, to sufficiently discover the possible interconnections between cognitive functioning and language in preschool students learning a second language.

\section{ACKNOWLEDGEMENT}

This study was supported by Applied Linguistics Research Lab (ALLAB) at Prince Sultan University.

\section{REFERENCES}

Baddeley, A. (2003). Working memory and language: An overview. Journal of communication disorders, 36(3), 189-208

Baddeley, A. D. (1986). Working memory. Oxford University Press.

Baddeley, A., \& G. J. Hitch. (1974). Working Memory. In G. Bower (Ed.), Recent advances in learning and motivation (pp. 47-89). Academic Press.

Beatty-Martínez, A. L., \& Dussias, P. E. (2017). Bilingual experience shapes language processing: Evidence from codeswitching. Journal of Memory and Language, 95, 173-189. doi.org/10.1016/j.jml.2017.04.002

Bialystok, E. (2011). Coordination of executive functions in monolingual and bilingual children. Journal of experimental child psychology, 110(3), 461-468. 
Burgaleta, M., Sanjuán, A., Ventura-Campos, N., Sebastian-Galles, N., \& Ávila, C. (2016). Bilingualism at the core of the brain. Structural differences between bilinguals and monolinguals revealed by subcortical shape analysis. NeuroImage, 125, 437-445.

Buchsbaum, B. R., \& D'Esposito, M. (2008). The search for the phonological store: From loop to convolution. Journal of Cognitive Neuroscience, 20(5), 762-778.

Coady, M. R. (2020). The Coral Way Bilingual Program. Bristol, United Kingdom: Multilingual Matters.

Cowan, N., Nugent, L. D., Elliott, E. M., Ponomarev, I., \& Saults, J. S. (1999). The role of attention in the development of short-term memory: Age differences in the verbal span of apprehension. Child Development, 70(5), 1082-1097.

Dos Santos, C., \& Ferré, S. (2018). A nonword repetition task to assess bilingual children's phonology. Language Acquisition, 25(1), 58-71. doi.org/10.1080/10489223.2016.1243692

Ellis, N. C., \& Hennelly, R. A. (1980). A bilingual word-length effect: Implications for intelligence testing and the relative ease of mental calculation in Welsh and English. British Journal of Psychology, 71(1), 4351 .

Engel de Abreu, P. M. (2011). Working memory in multilingual children: Is there a bilingual effect? Memory, 19(5), 529-537.

Gámez, P. B., Griskell, H. L., Sobrevilla, Y. N., \& Vazquez, M. (2019). Dual language and English-only learners' expressive and receptive language skills and exposure to peers' language. Child Development, 90(2), 471-479. doi.org/10.1111/cdev.13197

Gathercole, S. E., \& Baddeley, A. D. (1990). The role of phonological memory in vocabulary acquisition: A study of young children learning new names. British Journal of Psychology, 81(4), 439-454. doi.org/10.1111/j.2044-8295.1990.tb02371.x

Gathercole, S. E., \& Hitch, G. J. (1993). Developmental changes in short-term memory: A revised working memory perspective. Theories of memory, 1, 189-209.

García, O., Lin, A., \& May, S. (Eds.). (2017). Bilingual and multilingual education. Springer.

Gass, S. M. (2013). Second language acquisition: An introductory course. Routledge.

Guijarro-Fuentes, P. (2019). Cross-linguistic influence in bilingual language acquisition: Determining onset and end. Probus, 31(2), 233-244. doi.org/10.1515/probus-2016-0010

Hackman, D. A., Gallop, R., Evans, G. W., \& Farah, M. J. (2015). Socioeconomic status and executive function: Developmental trajectories and mediation. Developmental Science, 18(5), 686-702.

Henderson, K. I. (2017). Teacher language ideologies mediating classroom-level language policy in the implementation of dual language bilingual education. Linguistics and Education, 42, 21-33. doi.org/10.1016/j.linged.2017.08.003

Johnson, S. I., García, O., \& Seltzer, K. (2019). Biliteracy and translanguaging in dual-language bilingual education. In D. DeMatthews \& E. Izquierdo (Eds.) Dual language education: Teaching and leading in two languages. Language policy (Vol. 18, pp. 119-132). Springer.

Johannessen, B. G. G. (Ed.). (2019). Bilingualism and bilingual education: Politics, policies and practices in a globalised society. Springer.

Kehoe, M., \& Mélanie, H. A. V. Y. (2019). Bilingual phonological acquisition: The influence of languageinternal, language-external, and lexical factors. Journal of Child Language, 46(2), 292-333. doi.org/10.1017/S0305000918000478

Kohonen, V., \& Service, E. (1995). Is the relation between phonological memory and foreign language learning accounted for by vocabulary acquisition? Applied Psycholinguistics 16(2), 155-172. doi.org/10.1017/S0142716400007062

Kormos, J., \& Sáfár, A. (2008). Phonological short-term memory, working memory and foreign language performance in intensive language learning. Bilingualism, 11(2), 261.

Kremin, L. V., Arredondo, M. M., Hsu, L. S. J., Satterfield, T., \& Kovelman, I. (2019). The effects of Spanish heritage language literacy on English reading for Spanish-English bilingual children in the US. International Journal of Bilingual Education and Bilingualism,22(2), 192-206. doi.org/10.1080/13670050.2016.1239692

Kroll, J. F., \& Ma, F. (2018). The bilingual lexicon. Wiley-Blackwell.

Linck, J. A., Osthus, P., Koeth, J. T., \& Bunting, M. F. (2014). Working memory and second language comprehension and production: A meta-analysis. Psychonomic bulletin \& review, 21(4), 861-883.

Marini, A., Eliseeva, N., \& Fabbro, F. (2019). Impact of early second-language acquisition on the development of first language and verbal short-term and working memory. International Journal of Bilingual Education and Bilingualism, 22(2), 165-176.

Marini, A., Marotta, L., Bulgheroni, S., \& Fabbro, F. (2015). Batteria per la Valutazione del Linguaggio in Bambini dai 4 ai 12 anni (Battery for Language Assessment in Children from 4 to 12 years). Giunti OS. 
Morales, J., Calvo, A., \& Bialystok, E. (2013). Working memory development in monolingual and bilingual children. Journal of Experimental Child Psychology, 114(2), 187-202. doi.org/10.1016/j.jecp.2012.09.002

Morales, J., Gómez-Ariza, C. J., \& Bajo, M. T. (2013). Dual mechanisms of cognitive control in bilinguals and monolinguals. Journal of Cognitive Psychology, 25(5), 531-546. doi.org/10.1080/20445911.2013.807812

O’Toole, C., \& Hickey, T. M. (2013). Diagnosing language impairment in bilinguals: Professional experience and perception. Child Language Teaching and Therapy,29(1), 91-109. doi.org/10.1177/0265659012459859

Ozfidan, B., \& Mitchell, C. (2020). Detected difficulties in argumentative writing: The case of culturally and linguistically Saudi backgrounded students. Journal of Ethnic and Cultural Studies, 7(2), 15-29.

Ozfidan, B., \& Burlbaw, L. M. (2019). A literature-based approach on age factors in second language acquisition: Children, adolescents, and adults. International Education Studies, 12(10). 27-36.

Ozfidan, B., \& Toprak, M. (2019). Cultural awareness on a bilingual education: A mixed method study. Multicultural Learning and Teaching, 17(4), 250-261.

Ozfidan, B., \& Demir, H. (2014). Bask çift dilli eğitimi ve bunun Türkiyedeki olasi çift dilli eğitim için örneklendirilmesi. Asian Journal of Instruction, 2(1) 77-85.

Parker-Jones, O., Green, D. W., Grogan, A., Pliatsikas, C., Filippopolitis, K., Ali, N., Lee, H. L., Ramsden, S., Gazarian, K., Prejawa, S., Seghier, M. L., \& Price, C. J. (2012). Where, when and why brain activation differs for bilinguals and monolinguals during picture naming and reading aloud. Cerebral Cortex, 22(4), 892-902. doi.org/10.1093/cercor/bhr161

Peets, K. F., Yim, O., \& Bialystok, E. (2019). Language proficiency, reading comprehension and home literacy in bilingual children: The impact of context. International Journal of Bilingual Education and Bilingualism, 1-15. doi.org/10.1080/13670050.2019.1677551

Raven, J. (2000). The Raven's progressive matrices: Change and stability over culture and time. Cognitive psychology, 41(1), 1-48.

Service, E. (1992). Phonology, working memory, and foreign-language learning. The Quarterly Journal of Experimental Psychology, 45(1), 21-50. doi.org/10.1080/14640749208401314

Schwartz, S., Shinn-Cunningham, B., \& Tager-Flusberg, H. (2018). Meta-analysis and systematic review of the literature characterising auditory mismatch negativity in individuals with autism. Neuroscience \& Biobehavioral Reviews, 87, 106-117. doi.org/10.1016/j.neubiorev.2018.01.008

Shin, S. J. (2017). Bilingualism in schools and society: Language, identity, and policy. Routledge.

Wechsler D. (1993). WISC-R. Scala d'Intelligenza Wechsler per Bambini Riveduta. Giunti O.S. Organizzazioni Speciali.

Ziglari, L., \& Ozfidan, B. (2016). Self-and other-repairs in child-adult interaction: A case study of a pair of persian-speaking twins. International Journal of English Linguistics, 6(4), 52-59.

Zavala, V. (2018). Language as social practice: Deconstructing boundaries in intercultural bilingual education. Trabalhos em Linguística Aplicada, 57(3), 1313-1338. 